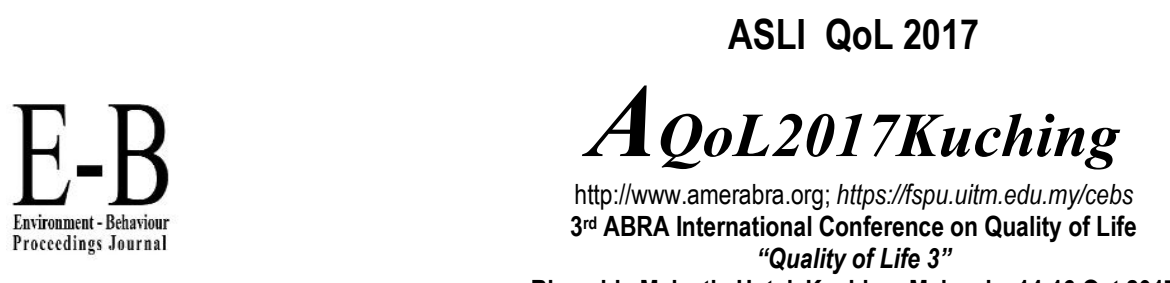

Riverside Majestic Hotel, Kuching, Malaysia, 14-16 Oct 2017

\title{
Effect of Motorcycling on Salivary Noise-Induced Cortisol among Young Motorcyclists
}

\author{
Anila Ali1,3, Nazri Che Dom¹, Roslinah Mohamad Hussain², Mujid Abdullah¹ \\ 1Department of Environmental Health and Safety, Faculty of Health Sciences, Universiti Universiti Teknologi MARA, Selangor Malaysia \\ 2Department of Medical Imaging Technology, Faculty of Health Sciences, Universiti Universiti Teknologi MARA, Selangor Malaysia \\ ${ }^{3}$ Department of Environmental Management and Policy, Faculty of Engineering, Balochistan \\ University of Information Technology, Engineering and Management Sciences, Quetta, Pakistan \\ anila928@yahoo.com \\ $+60-11-26258324$
}

\begin{abstract}
Saliva cortisol response was investigated from the motorcycling exposure for approximately 50 minutes between low and high noisesensitive (Weinstein Noise Sensitivity Scale) young riders $(19-25$ years). The results showed significant difference $(p<0.05)$ in salivary cortisol concentrations in High-Noise Sensitive group $(n=27)$. Significant gender differences were found $(p<0.05)$ among the Low-Noise sensitive group $(n=30)$, after ride. Cross-analysis between groups was significant $(p<0.05)$ for before ride cortisol levels of Low-Noise sensitive group. This study suggests that subjective noise sensitivity plays a vital role in increased cortisol level among noise sensitive riders.
\end{abstract}

Keywords: Noise, Salivary cortisol, Noise sensitivity, motorcycle.

eISSN: 2398-4287@ 2017. The Authors. Published for AMER ABRA by e-International Publishing House, Ltd., UK. This is an open access article under the CC BYNCND license (http://creativecommons.org/licenses/by-nc-nd/4.0/). Peer-review under responsibility of AMER (Association of Malaysian Environment-Behaviour Researchers), ABRA (Association of Behavioural Researchers on Asians) and cE-Bs (Centre for Environment-Behaviour Studies), Faculty of Architecture, Planning \& Surveying, Universiti Teknologi MARA, Malaysia. https://doi.org/10.21834/e-bpj.v2i6.936

\section{Introduction}

The motorcycle is one of the noisiest forms of transportation. Besides being exposed to the engine noise while riding, motorcyclists also experience turbulent airflow around the helmet, which produces continuous loud noise termed as the "wind noise" (McCombe, 2003. Previous report has confirmed excessive wind noise as experienced by the rider, ranging from $90 \mathrm{dBA}$ at $45 \mathrm{mph}$ and increasing to $110 \mathrm{dBA}$ at $100 \mathrm{mph}$ (Ross, 1989). On open roads, wind noise ranges between $63 \mathrm{dBA}$ to $90 \mathrm{dBA}$ (up to $105 \mathrm{dBA}$ ), whereas, in general, riders are exposed to noise levels ranging from 90 to 103 dBA (McCombe, 2003; Jordan, Hetherington, Woodside, \& Harvey, 2004). Such high-intensity noise can lead to auditory (hearing deficits), and non-auditory health affects varying in physiological and psychological detrimental impacts (World Health Organization, 2011).

Noise is regarded as an environmental stressor, an unwanted sound that creates the feeling of unpleasantness and nuisance. It is a psychosocial and environmental stressor that can activate the sympathetic and neuroendocrine systems. In humans, the primary physiological stress response is the activation of the hypothalamus-pituitary-adrenal (HPA) axis, which under chronic nature involves a long-lasting activation (Lefèvre et al., 2017). Stressors create a physiological response in the body, which stimulates the glucocorticoid hormone known as cortisol (Lupien et al., 2005), which is viewed as a valid indicator of stress Marques, Silverman, \& Sternberg, 2010). In response to stress, cortisol plays a vital role in regulating metabolism and homeostasis process (Evans, Lercher, Meis, Ising, \& Kofler, 2001), as well as initiating adaptive processes for beneficial energy but the prolonged secretion becomes harmful, resulting

eISSN: 2398-4287@ 2017. The Authors. Published for AMER ABRA by e-International Publishing House, Ltd., UK. This is an open access article under the CC BYNCND license (http://creativecommons.org/licenses/by-nc-nd/4.0/). Peer-review under responsibility of AMER (Association of Malaysian Environment-Behaviour Researchers), ABRA (Association of Behavioural Researchers on Asians) and cE-Bs (Centre for Environment-Behaviour Studies), Faculty of Architecture, Planning \& Surveying, Universiti Teknologi MARA, Malaysia.

https://doi.org/10.21834/e-bpj.v2i6.936 
in risk factors for diseases. In the presence of a stressor, cortisol concentration increases regardless of the circadian cycle (Kristenson, Garvin, \& Lundberg, 2011).Cortisol is articulated in some studies to be associated with adverse physiological and psychological reactions such as increased blood pressure, hypertension annoyance, memory deficits, communication difficulties, fatigue and aggression which in the long-term leads to advanced health issues (Stansfeld S A and Matheson M P, 2003).

Cortisol can be measured using saliva, urine or blood plasma. Level of cortisol concentration in saliva is sensitive towards acute stressors in daily activities, such as noise (Waye et al., 2002). Saliva cortisol has been validated as plasma-free cortisol concentration measurement, presenting a biomarker of a stress reaction to noise exposure (Bigert, Bluhm, \& Theorell, 2005). Collection of saliva samples have achieved recognition because the procedure is feasible, noninvasive, standardized and easy to handle in field studies related to noise research (Bigert et al., 2005). For standardized collection, different collection devices are available as described in previous studies, including passive droll technique (Stokholm et al., 2014), and oral swabs (Hill, 2012). Studies related to noiseinduced cortisol secretion have been conducted on occupational (Stokholm et al., 2014), rail and road traffic noise (Bigert et al., 2005), air traffic noise (Lefèvre et al., 2017) and some laboratory based experimental studies (Ljungberg \& Neely, 2007. These studies have employed different investigation methods of cortisol, such as focusing on the average level of cortisol at specific times of the day (diurnal rhythm) (Bigert et al., 2005), and on the CAR (cortisol awakening response) (Hill, 2012).

Noise sensitivity, as a predictor and moderator of health outcomes and well-being, has gained interest in the past years (Hill, 2012). It plays a significant role on the impact of environmental noise on health and well-being (Kishikawa et al., 2006). Job (1999) described noise sensitivity as a personal trait encompassing internal factors (e.g., physiological, psychology, attitudinal) that increase an individual's susceptibility to the effects of noise (R. F. S. Job, 1999). Noise sensitivity is considered as a personality trait that determines individual's reaction to noise (Ellermeier, Eigenstetter, \& Zimmer, 2001) and a personal vulnerability, which acts as confounding factor (R. F. Job et al., 2001). Individual categorized as high-noise sensitive tends to get more affected by the exposed noise than the individuals who are insensitive, merely because of coping abilities with noise (Black, Black, Issarayangyun, \& Samuels, 2007). The level of noise sensitivity determines the attitude and perception given to any noise stimulus for subsequent physiological and psychological reaction. Measuring of noise sensitivity through self-reported structured questionnaire such as Weinstein Noise Sensitive Scale, developed by Weinstein, is considered to be a popular scale used in many international publications (Black et al., 2007).

Noise sensitivity and poor health outcomes are related with one and another as it moderates the association between noise exposure and health outcomes (Shepherd, Welch, Dirks, \& Mathews, 2010) Noise sensitivity plays an important role in better understanding the elevated cortisol levels. Previous studies suggest a lower threshold for physiological stress reactivity among noise sensitive individual (Waye et al., 2002). Furthermore, if an individual is experiencing a prolonged noise exposure, then the probability of losing sensitivity to that particular stimulus (i.e., adaptation) increases (Chung, To, Lai, \& Choy, 2014).

Motorcyclists psychological health related studies are scarce, while research on rider's noise-induced cortisol arousals has not been investigated previously. This study is important for investigating the possible impact of noise experienced due to motorcycling on riders stress reactivity and its relation to noise sensitivity. Therefore, this study aimed to determine the effects of noise exposed during motorcycle ride on differential effects on their cortisol concentration and to evaluate the influence of noise sensitivity on the cortisol reactivity.

\subsection{Methodology}

\subsection{Study participants}

A cross-sectional study based on survey and field experiment was conducted on undergraduate University students at Universiti Teknologi Mara, Kampus Puncak Alam Malaysia. Samples were collected through simple random sampling technique across different faculties, representing from all over Malaysia (Masuri, Dahlan, Danis, \& Isa, 2017); (Masuri, Isa, \& Tahir, 2012). To be eligible for the study, participants had to be: (i) between 19 to 25 years old (Norfazila, Mustaffa, \& Ghazali, 2017); (ii) nonsmoker; (iii) absence of chronic diseases; (iv) riding motorcycle as primary means of transportation; and (v) helmet-riding behavior. A set of structured questionnaires consisted of study information sheet, respondent's demographic questionnaire and Weinstein Noise Sensitivity Scale (WNSS) were distributed among 356 motorcyclists, while 330 returned the questionnaire. A total of 301 respondents was recruited for the study based on inclusion and exclusion criteria. All participants endorsed written consent form of participation before a commencement of the study. Later, based on WNSS score, the total of 57 respondents gave consent for participating in the noiseinduced cortisol motorcycling field experiment. Study procedure and design were approved by Faculty's (Health Sciences) Internal Ethical Committee, Universiti Teknologi Mara.

\subsection{Study Instruments}

\subsubsection{Demographic Information}

The participant's demographic data was obtained through a self-reported questionnaire, which consisted of data related to age, gender, years of motorcycling experience (as a primary mode of transportation), faculty, the semester of enrollment, motorcycle license, usage of the helmet, smoking habit and presence of any chronic diseases. 


\subsubsection{Weinstein Noise Sensitivity Scale}

The self-reported standardized noise-sensitivity test widely known as Weinstein Noise Sensitivity Scale (WNSS) was adopted for this study. The 21-item test is based on six-point Likert-type scale, ranging from "disagree strongly" to "agree strongly." The scores ranged between 21 to 126, i.e., minimum and maximum respectively. Previous researchers, both from the field and experimental studies have tested satisfactory psychometric properties, predictive validity and internal consistency of the questionnaire, which ranged from 0.84 to 0.87 (Kuder-Richardson reliability).(Weinstein, 1978).

\subsubsection{Saliva collection instruction}

Before saliva collection, respondents were provided with saliva collection instructions preceding the actual saliva sample collection to avoid contamination in the oral cavity, to control pH level and increased levels of cortisol concentrations in saliva (Saiyudthong, Suwannarat, Trongwongsa, \& Srisurapanon, 2010. Instructions were categorized mainly into four components. First, the night before sample collection, participants had to avoid anti acids, bismuth medications, mouth wash, lotions or cream on the face. Second, on the day of sample collection, participants had to avoid eating chocolate, onions, garlic, or cruciferous such as cauliflower, broccoli, and cabbage. Among drinking items to be avoided are tea, coffee and caffeinated drinks such as soda and Guarani. Third, one hour before saliva collection teeth should not have brushed. Fourth, 10 minutes before sample collection, respondents had to rinsed their mouth thoroughly for 30 seconds with cold water to remove food residues. (Elbüken et al., 2014)

\subsubsection{Saliva collection procedure}

Passive drool method was used for collecting a saliva sample. Participants were instructed to tilt their head forward for increased secretion of saliva into the oral cavity and transfer directly into a $2 \mathrm{ml}$ saliva collection polypropylene vial (Shirtcliff et al., 2015). Samples that were contaminated with blood were discarded and repeated with 10 minutes break after mouth was rinse with cold water. After sample collection, the time and date of collection and sample code were inscribed on the vial and data logged. Saliva samples were stored within 30 minutes of collection at $-80^{\circ} \mathrm{C}$ (Elbüken et al., 2014). The maximum storage of samples was seven months before ELISA analysis (Waye et al., 2002).

\subsection{Study Procedure}

Figure 1 illustrates the study procedure where motorcycle riders noise-sensitivity was investigated and scored into three categories: High-Noise Sensitive (H-NS) group, Moderate-Noise Sensitive group, and Low-Noise Sensitive (L-NS) group. For exploring the differences in salivary cortisol concentration due to motorcycling exposure, respondents from only the H-NS group and L-NS group were recruited for the field experiment.

On the field-experiment day, participants were requested to bring their motorbike to the testing site. Before testing, saliva instructions confirmation checklist was obtained from participants, followed by a relaxing 10 minutes, followed by saliva collection as "before ride" sample. Subsequently, participants commenced from destination D1 (UiTM, Puncak Alam, Faculty of Education bus stop) to D2 (Uitm Perdana) and returned to D1, for approximately 45 minutes ride, to ensure the maximum arousal of cortisol concentration (Sylvie Hebert \& Lupien, 2009). Immediately, upon the arrival at D1 via D2, saliva collected as "after ride" sample. Saliva samples were stored in aliquots at $-80^{\circ}$ to avoid repeated freeze thaw.

Saliva cortisol concentration was measured in triplicate by enzyme immunoassay (EIA) technique by using the High-sensitivity human salivary cortisol-ELISA (enzyme-linked immunosorbent assay) kit (Salimmetrics, State College, PA, USA). Kits were stored at 4 to $8^{\circ} \mathrm{C}$ prior to testing. ELISA analysis was followed according to the manufacturer's instructions (Salimetrics, 2014) and the cortisol measurements were obtained at the optical density of $450 \mathrm{~nm}$. The coefficients of variation (CV) were calculated from the means of triplicated saliva cortisol assay. The intra and inter assay CV's were less than $5 \%$ and $15 \%$ respectively. The cortisol concentrations were expressed in $\mu \mathrm{g} / \mathrm{dL}$.

\subsection{Statistical analysis}

Participants information data and cortisol concentration values were tabulated and logged on excel worksheet for database and computed for statistical analysis through Statistical Package for Social Sciences, IBM SPSS (Version 22 Inc., Chicago, IL). Descriptive data of variables, i.e., age, gender, years of riding the motorcycle, helmet usage was obtained through frequency table while the relationship between variables was computed through cross-tabulation. Data distribution was found not normally distributed through Shapiro-Wilk test. Due to the non-homogenous distribution of data, non-parametric tests were conducted for statistical analysis. To evaluate the differences between before and after ride cortisol concentration in L-NS and H-NS, Wilcoxon Sign ranked test was conducted, whereas, gender differences of L-NS and H-NS groups cortisol concentration before and after the motorcycle ride was determined through two samples independent tests (Mann-Whitney U-test). Cross-analysis were also conducted between the two groups before and after ride cortisol concentrations through Welch t-test. Bar charts and box and whiskers were plotted to demonstrate the mean and median differences of saliva cortisol concentration for both the groups before and after motorcycle ride. An alpha level of 0.05 was used for subsequent analysis. 


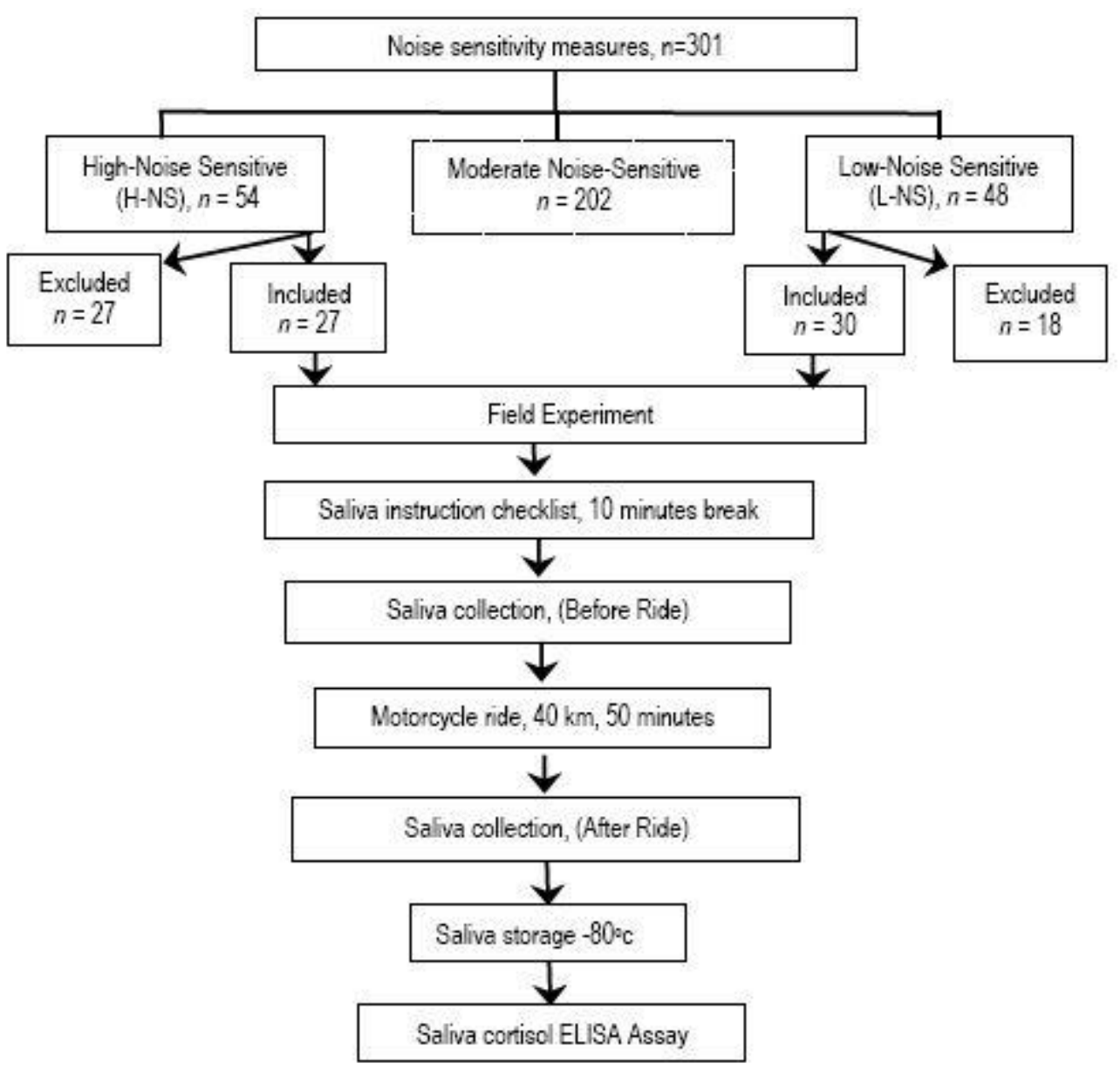

Figure 1: Study Procedure: Participants distribution from noise-sensitivity to field experiment, process of salivary cortisol collection and cortisol measurements (ELISA-assay)

\subsection{Results}

\subsection{Noise sensitivity}

The estimated value of coefficient of reliability for the internal consistency for WNSS items was statistically reliable, $\alpha_{c}=0.776$ though Cronbach's alpha $(n=301)$. Division of the noise sensitivity (NS) groups constituted into low-noise sensitive (L-NS) $($ WNSS (mean) $=6$ $5.72 \pm S D, 4.36 ; n=48)$, moderate-noise sensitive (M-NS) $\left(W_{N S S}\right.$ (mean) $\left.=82.49 \pm S D, 6.7 ; n=202\right)$ and high-noise sensitive (H-NS) $\left(W N S S_{\text {(mean) }}=101.8 \pm S D, 5.31 ; n=54\right)$. For the field experiment, a total 57 riders consented to participate, i.e. 27 riders from H-NS group and 30 riders from L-NS group.

\subsection{Descriptive profile of participants of the field experiment}

Table 1 presents the demographic profile of the participants $(n=57)$ recruited in the field experiment for exploring the effects of noiseinduced salivary cortisol concentration before and after the motorcycle ride. Participation was dominated by male riders $(n=40,70 \%)$ than female riders $(n=17,30 \%)$. Participants mean age was $22.02(S D=1.172)$ which ranged from 19 to 25 years. Participation of motorcyclists ranged from semester 1 till 8 , with the mean of $4.77(S D=1.40)$ while driving age ranged from 1 to 12 years, with mean driving age of $6.8(S D=2.747)$.

The L-NS group consisted of $24(80 \%)$ males and $6(20 \%)$ females. Participants mean age was $21.90(S D=1.34)$ which ranged from 20 to 25 years. Participation of respondents represented from semester 1 to 7 , with a mean semester of $4.56(S D=1.43)$ while driving age ranged from 1 to 12 years of experience, with a mean driving age of $7.07(S D=3.107)$. H-NS group constituted $16(59 \%)$ males and $11(41 \%)$ females. Participants mean age was $22.95(S D=0.95)$ which ranged between 19 to 24 years. Participation of motorcyclists enrolled from semester 2 till 8 , a mean of $5.0(S D=1.3)$ while driving age ranged between 2 to 10 years of experience, with a mean driving age of $6.52(S D=2.31)$. 
Table 1: Demographic profile of motorcyclists who participated in the field experiment

\begin{tabular}{|c|c|c|c|}
\hline Variables & $\begin{array}{l}\text { Total } \\
N=57\end{array}$ & $\begin{array}{l}\text { L-NS group } \\
n=30\end{array}$ & $\begin{array}{l}\text { H-NS group } \\
n=27\end{array}$ \\
\hline Gender (M/F) & $\begin{array}{l}40 / 17 \\
M \pm S D, \text { range } \\
\end{array}$ & $\begin{array}{l}24 / 6 \\
M \pm S D, \text { range }\end{array}$ & $\begin{array}{l}16 / 11 \\
M+S D, \text { range }\end{array}$ \\
\hline Age, (yrs.) & $22.02 \pm 1.172,19-25$ & $21.90 \pm 1.34,20-25$ & $22.15 \pm .95,19-24$ \\
\hline Semester & $4.77 \pm 1.40,1-8$ & $4.56 \pm 1.43,1-7$ & $5.0 \pm 1.3,2-8$ \\
\hline Driving age & $6.807 \pm 2.747,1-12$ & $7.07 \pm 3.107,1-12$ & $6.52 \pm 2.31,2-10$ \\
\hline
\end{tabular}

\subsection{Cortisol concentration analysis}

The Low-Noise Sensitive(L-NS) group mean concentration of cortisol before and after motorcycle ride was $0.17 \pm 0.11 \mu \mathrm{g} / \mathrm{dL}$ (ranged: $0.04-0.47$ ) and $0.15 \pm 0.06 \mu \mathrm{g} / \mathrm{dL}$ (ranged: $0.04-0.35$ ) respectively. Results among L-NS riders indicated that there was no significant difference between before and after ride cortisol concentration, $\underline{z}=-1.502, p=0.133$. Results showed that participants with low noise sensitivity showed no effect on their cortisol concentrations after motorcycle ride exposure. The median $(0.148 \mu \mathrm{g} / \mathrm{dL})$ cortisol concentration before ride among L-NS group is shown in box-plot (Figure 2A) indicates slightly higher than after ride cortisol concentration median $(0.135 \mu \mathrm{g} / \mathrm{dL})$. It was also observed that cortisol concentration interquartile range before ride $(0.102-0.253$ $\mu \mathrm{g} / \mathrm{dL})$ was higher than after ride $(0.106-0.186 \mu \mathrm{g} / \mathrm{dL})$. Overall, before ride L-NS group cortisol levels were higher than after motorcycling exposure.

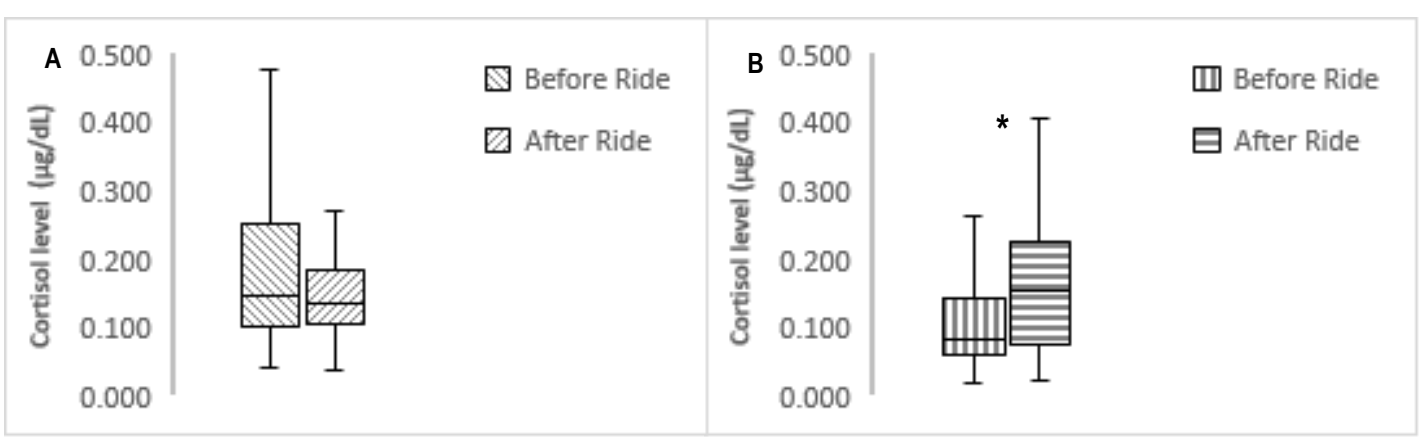

Figure 2: Salivary cortisol concentration differences between "before" and "after" ride: (A) Low-Noise Sensitive group (B) High-Noise Sensitive Group. Note: $\left({ }^{*}\right) p$-value $<0.05$ between before ride and after ride.

High- Noise Sensitive (H-NS) group mean concentration of cortisol before and after motorcycle ride was $0.12 \pm 0.08 \mu \mathrm{g} / \mathrm{dL}$ (ranged: $0.019-0.35$ ) and $0.16 \pm 0.1 \mu \mathrm{g} / \mathrm{dL}$ (ranged: $0.02-0.41$ ), respectively. Statistical analysis revealed significant increase in $\mathrm{H}$ NS group cortisol levels after the motorcycle ride, $\underline{z}=-2.667, p=0.008$. Box-plot (Figure 2B) illustrates H-NS group cortisol concentration levels comparison between before and after motorcycle ride. It shows significantly higher median $(0.155 \mu \mathrm{g} / \mathrm{dL})$ concentration of cortisol levels after riding compared to before ride $(0.084 \mu \mathrm{g} / \mathrm{dL})$. The cortisol concentration interquartile range after ride $(0.078-0.228 \mu \mathrm{g} / \mathrm{dL})$ was higher than before motorcycle ride $(0.061-0.143 \mu \mathrm{g} / \mathrm{dL})$. Results indicated that participants with highnoise sensitivity had increased cortisol concentration after motorcycling exposure.

\subsubsection{Gender differences}

Genders effects on cortisol concentrations in L-NS and H-NS group were analysed for both before and after motorcycling exposure. For the L-NS group, no significant difference was found in cortisol concentrations before motorcycle ride among males and females, $U$ $=56, p=0.407, r=0$. However, mean ranks for the female riders showed higher ranks (18.17) compared to male riders (14.83). Figure $3 \mathrm{~A}$ presents overlapping error bars indicating no noticeable difference between male and female cortisol concentrations before motorcycle ride in the L-NS group.

Moreover, after ride cortisol concentration was significantly higher among female riders $\left(M_{\text {ranks }}=22.08\right)$ than male participants ( $M$ ranks $=13.85), U=32.50, p=0.040, r=0.04$.) in the L-NS group. Figure 3B presents less overlapping error bar indicating significantly increased cortisol concentration among female rider's than male riders after motorcycle ride in the L-NS group. Results indicated that female riders from L-NS group had increased cortisol level than male motorcycle riders.

High-Noise sensitive (H-NS) group showed no significant gender difference in cortisol concentration before $(U=88, p=1.00, r=$ $0.159)$ and after motorcycle ride $(U=83.00, p=0.805, r=0.394)$. Before ride, both genders had equal mean ranks (14) as shown in Figure $3 \mathrm{C}$ and $3 \mathrm{D}$ with overlapping error bar, whereas, after ride females had slightly higher value (14.45) than males (13.69). 


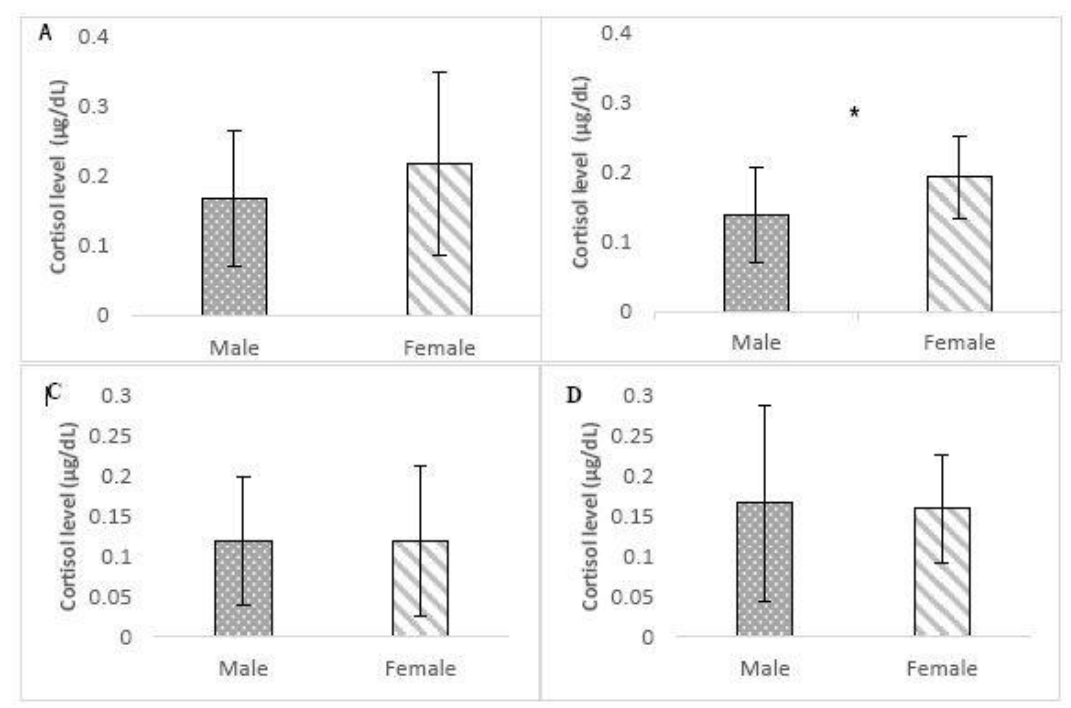

Figure 3: Gender difference in cortisol concentration: (A) "Before ride" among the Low-Noise Sensitive group; (B) "After ride" among the Low-Noise Sensitive group; (C) "Before ride" among the High-Noise Sensitive group; (D)"After ride" among the High-Noise Sensitive group. Note: $\left(^{*}\right) p$-value $<0.05$ between males and females.

\subsubsection{Cross-analysis among groups}

The participant's cortisol concentration before and after motorcycle ride were cross analysed between the two studied groups (L-NS and H-NS) through Welch t-test. Cortisol concentration before ride between L-NS $(M=0.17, S D=.1049)$ and H-NS groups $(M=$ $0.119, S D=0.0853$ ) was found statistically significant, $F(1,54.47)=5.446, p=0.023$. Cross-analysis for before motorcycle ride among groups is shown in box-plot (Figure 4A) which indicates that L-NS riders had higher median cortisol concentration $(0.148$ $\mu \mathrm{g} / \mathrm{dL})$ compared to $\mathrm{H}-\mathrm{NS}$ riders $(0.084 \mu \mathrm{g} / \mathrm{dL})$ with higher cortisol concentration interquartile range for before ride of L-NS $(0.102-$ $0.253 \mu \mathrm{g} / \mathrm{dL})$ compared to the H-NS $(0.061-0.143 \mu \mathrm{g} / \mathrm{dL})$. Cortisol concentration between L-NS $(M=0.148, S D=0.069)$ and H-NS group $(M=0.163, S D=0.1013)$ after motorcycle ride was found non-significant, $F(1,45.340)=0.400, p=0.530$. It is shown in boxplot (Figure 4B) which indicates that H-NS riders had higher median cortisol concentration $(0.155 \mu \mathrm{g} / \mathrm{dL})$ than $\mathrm{L}-\mathrm{NS}$ riders $(0.135 \mu \mathrm{g} / \mathrm{dL})$ with higher interquartile range of after ride cortisol concentration for the H-NS group $(0.078-0.228 \mu \mathrm{g} / \mathrm{dL}) \mathrm{compared}$ to L-HS group $(0.106-0.186 \mu \mathrm{g} / \mathrm{dL})$.

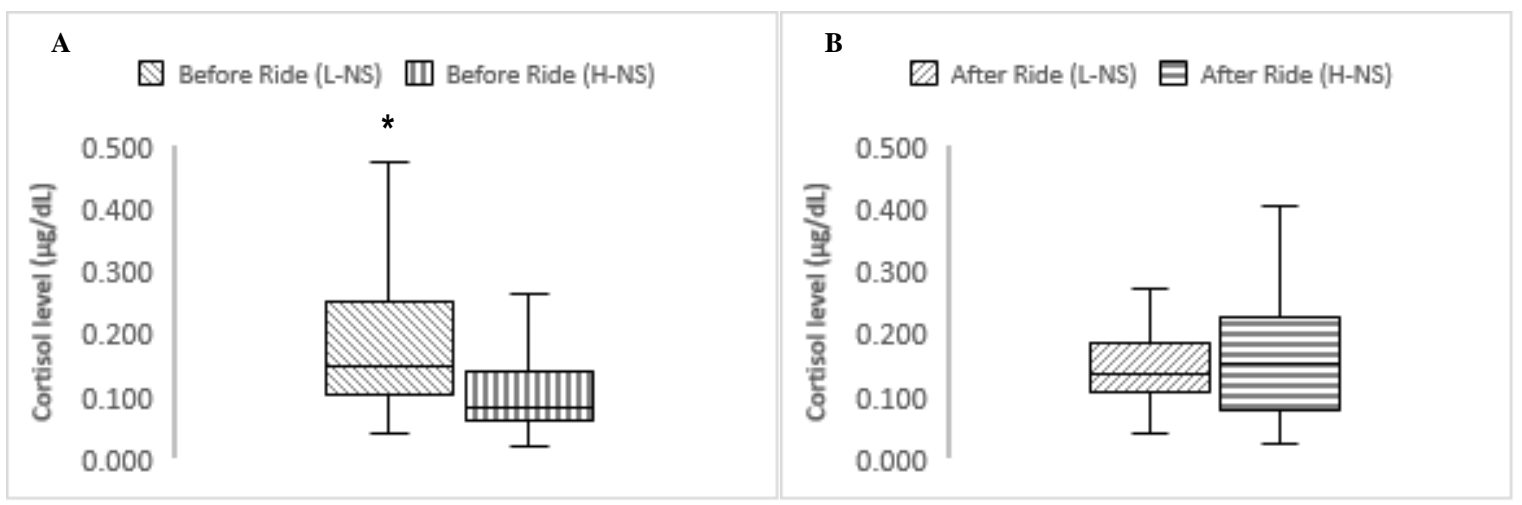

Figure 4: Cross-analysis among groups between before ride and after ride cortisol differences: (A) Cortisol concentration difference "Before ride" between Low and High-Noise Sensitive group; (B) Cortisol concentration difference "After ride" between Low and High-Noise Sensitive. Note: $\left(^{*}\right) p$-value $<0.05$.

\subsection{Discussion}

This study carried out a noise sensitivity assessment of young motorcyclists $(n=301)$ which revealed that a majority $(66.7 \%)$ of the motorcyclist population encompasses the moderate level of noise sensitivity, while $15.3 \%$ and $18 \%$ riders constituted under low and high noise sensitivity respectively. The results suggested that minor percentage of the riders were at the two extreme points of the noise sensitivity scale. Previous studies reported similar results on different populations by concluding that minor population exhibits higher noise-sensitivity traits with greater susceptibility of health risk associated with it (Kishikawa et al., 2006; Oiamo, Luginaah, \& Baxter, 2015). 
On account of average motorcycling exposure, motorcycle riders may experience noise levels above $90 \mathrm{dBA}$, (Chris Jordan, Oliver Hetherington, Alan Woodside, 2004), which is sufficient for activation of HPA axis and release of cortisol for combating the acute stressor (Wagner et al., 2010). For precise investigation of noise-induced cortisol reactivity, young riders noise sensitivity was assessed and recruited from low and high noise-sensitive group for possible comparison in their stress response. Cortisol is related to an important health parameter including stress and effects on the immune system. Changes in cortisol levels, particularly related to the chronic stressful conditions exert an adverse impact on health (Waye et al., 2002). The focus on noise sensitivity investigation on public health research is rare, but the evidence suggests that noise sensitivity may be a health risk factor unto itself (Fyhri \& Klæboe, 2009)

In the field study, the effects of motorcycling exposure on salivary cortisol concentration were investigated to compare between high-noise sensitive (H-NS) riders with low-noise sensitive (L-NS) riders. During the day, cortisol tends to decline naturally, particularly in the morning. Therefore, differential effects of noise could be explained either regarding an evaluated level of cortisol from before to after riding exposure or regarding decline cortisol level, reflecting the extent of how stressful the motorcycling exposure has influenced on HPA axis. The findings of the current study revealed cortisol level to be positively associated with the high noise-sensitive group after the riding exposure $(p=0.008)$, while there was no significant difference in cortisol concentration before and after the ride among L-NS riders $(p=0.133)$.

As such our findings extend two previous laboratory studies which investigated the relation of noise-induced salivary cortisol assessment, the individual differences on a noise-sensitivity factor. The exemplary study performed by Waye (2002) exposed respondents to low-frequency noise and determined its relation to cortisol (salivary) and performance. Reported results illustrated the significant association between noise exposure for 2 hours with increased salivary cortical secretion and decreased performance in battery test among high noise sensitive test. The results also indicated that high noise-sensitive experience impaired cognitive performance under acute stressors (Waye et al., 2002). About Waye's study results, motorcyclists with high noise sensitivity may also experience impaired cognitive functioning during a commute and may behold risk factor to road accidents (Ali et al., 2016), which requires further investigation.

In contrast to our finding, Ljungberg and Neely (2007), reported no significant relation between salivary cortisol arousal with noise exposure among noise sensitivity participants. However, impaired cognitive performance was found among noise-sensitive individuals (Ljungberg \& Neely, 2007).

Another laboratory based study conducted by Wagner (2010) investigated the salivary stress biomarkers in relation to naturalistic noise exposure. The experimental design exposed the respondents to noise level up to $75 \mathrm{~dB}$ for 20 minutes, and saliva samples were collected before and after the noise exposure. The results reported the significant increase in cortisol levels from before to after test performance $(p=0.01$ ) (Wagner et al., 2010), despite the small sample size $(n=20)$ and noise sensitivity was not determined.

Similarly, another study by Hebert and Lupien (2007), also reported increased cortisol concentration after the artificially induced dose-response noise exposure in the laboratory setting. They also reported a significant association of increased cortisol in respondents who suffered from tinnitus and cortisol secretion, which peaked after about 30 minutes and then gradually dropped with a termination of noise (Sylvie Hebert \& Lupien, 2009).

The above-cited studies did not provide any gender analysis in their studies. Therefore, comparisons to this study in relation to other relevant studies are not possible. This study did not show any significant differences in gender cortisol concentration reactivity among high-noise sensitive riders $(p=0.407)$. In contrast, low-noise sensitive female riders showed significantly $(p=0.04)$ higher elevated cortisol concentration after undertaking the motorcycle ride, while no difference was computed before the ride. Overall, based on mean ranks, females were observed with higher cortisol concentration both before and after motorcycle ride.

Cross-analysis between categorized groups showed that L-NS riders tend to have significantly higher cortisol concentration the before ride $(p=0.023)$ from H-NS riders. These results increase the credibility of the analysis because the young motorcycle riders in the H-NS had significantly increased cortisol level after motorcycle exposure $(p=0.008)$ reflecting the acute stress response, while LNS higher cortisol before ride needs to be investigated for further explanation.

Psychosocial stress responds to threats by helping an organism by increasing cortisol secretion above baseline (Gunnar \& Quevedo, 2007). As reported the repeated chronic stress exposure and activation of HPA axis alter the function of the axis. Subsequently, dysregulation in HPA activity at rest and response to acute stress is associated with poor health outcomes (Repetti, Robles, \& Reynolds, 2011). To our knowledge, this study is the first to demonstrate the salivary cortisol reactivity based on real-field exposure.

The limitation of the study is primarily an examination of salivary cortisol to noise sensitivity, whereas other individual variables were not investigated such as sleeping patterns and disturbances, hearing status, personality traits and other salivary biomarkers. However, the strength of the study is the sample size presenting both categorized groups as H-NS and L-NS. Salivary cortisol samples were handled with care, and ELISA assay was conducted in triplicate for each sample. Furthermore, the results that we found reflects the acute noise-induced stress response rather than from long-term exposure to stress.

\subsection{Conclusion}

In conclusion, the results of the study reveal that the exposure of motorcycle to wind noise caused alterations in salivary cortisol concentration among subjects categorized as high-noise sensitive. No previous study explored the effects of motorcycling related to noise induced health effects on riders. Thus, this study provides the baseline for future research. 


\section{Acknowledgement}

The study was supported by CORE Shah Alam and Faculty of Health Sciences, UiTM Selangor, Puncak Alam Campus under Award Numbers 600-RMI/DANA 5/3 LESTARI (3/2015) and 600-RMI/MYRA 5/3 LESTARI (0016/2016).

\section{References}

Ali, A., Karuppannan, S., Hussain, R. M., Rajan, S., Abdullah, M., Ikhwan, R., \& Chinna, K. (2016). Epidemiological root cause analysis of noise and physio - psycho impacts related to motorcycle road accidents. Journal of Scientific Research and Development, 3(5), 150-156.

Bigert, C., Bluhm, G., \& Theorell, T. (2005). Saliva cortisol - a new approach in noise research to study stress effects. Int. J. Hyg. Environ.-Health, 208, 227-230.

Black, D. a., Black, J. a., Issarayangyun, T., \& Samuels, S. E. (2007). Aircraft noise exposure and resident's stress and hypertension: A public health perspective for airport environmental management. Journal of Air Transport Management, 13, 264-276.

Chris Jordan, Oliver Hetherington, Alan Woodside, H. H. (2004). Noise induced hearing loss in occupational motorcyclists. Journal of Environmental Health Research, 3.

Chung, A. W. L., To, W. M., Lai, T. M., \& Choy, Y. S. (2014). Characterizing noise sensitivity of inhabitants of cities. In 11th International Congress on Noise as aPublic Health Problem (pp. 1-8). Nara. Japan: ICBEN.

Elbüken, G., Köse, K., Karaca, Z., Tanrıverdi, F., Ünlühizarcı, K., Zararsız, G., \& Keleştimur, F. (2014). Comparison of Electrochemiluminescence and Enzyme Immunoassay Methods for the Measurement of Salivary Cortisol Tükrük Kortizolü Ölçümünde Elektrokemilüminesan ve Enzimimmünoassay Yöntemlerinin Karşılaştırııması, (15), 111-115.

Ellermeier, W., Eigenstetter, M., \& Zimmer, K. (2001). Psychoacoustic correlates of individual noise sensitivity. J. Acoust. Soc. Am., 109(4), 1464-1473.

Evans, G. W., Lercher, P., Meis, M., Ising, H., \& Kofler, W. W. (2001). Community noise exposure and stress in children. The Journal of the Acoustical Society of America, 109(3), 1023-1027.

Fyhri, A., \& Klæboe, R. (2009). Road traffic noise, sensitivity, annoyance and self-reported health-A structural equation model exercise. Environment International, 35(1), 91-97.

Gunnar, M., \& Quevedo, K. (2007). The Neurobiology of Stress and Development. The Annual Review of Psychology. Hill, E. M. (2012). Noise Sensitivity and Diminished Health : The Role of Stress-Related Factors. Doctoral Dissertation, Auckland University of Technology, (August)

Job, R. F., Hatfield, J., Carter, N. L., Peploe, P., Taylor, R., \& Morrell, S. (2001). General scales of community reaction to noise (dissatisfaction and perceived affectedness) are more reliable than scales of annoyance. The Journal of the Acoustical Society of America, 110(2), 939-946.

Job, R. F. S. (1999). Noise sensitivity as a factor influencing human reaction to noise. Noise \& Health, 1, 57-68.

Jordan, C., Hetherington, O., Woodside, A., \& Harvey, H. (2004). Noise induced hearing loss in occupational motorcyclists. Journal of Environmental Health Research, $3(2), 70-77$.

Kishikawa, H., Matsui, T., Uchiyama, I., Miyakawa, M., Hiramatsu, K., \& Stansfeld, S. a. (2006). The development of Weinstein's noise sensitivity scale. Noise \& Health, 8(33), 154-160.

Kristenson, M., Garvin, P., \& Lundberg, U. (2011). Psychosocial Work Stressors and Salivary The Role of Saliva Cortisol Measurement in Health and Disease Edited By. Bentham Science Publishers, 3-16.

Lefèvre, M., Carlier, M., Champelovier, P., Lambert, J., Laumon, B., Evrard, A., ... Bernard, U. C. (2017). Effects of aircraft noise exposure on saliva cortisol near airports in France. Occup Environ Med, 1-8.

Ljungberg, J., \& Neely, G. (2007). Stress, subjective experience and cognitive performance during exposure to noise and vibration. Journal of Environmental Psychology, 27, 44-54.

Lupien, S. J., Fiocco, A., Wan, N., Maheu, F., Lord, C., Schramek, T., \& Tu, M. T. (2005). Stress hormones and human memory function across the lifespan. Psychoneuroendocrinology, 30, 225-242.

Marques, A. H., Silverman, M. N., \& Sternberg, E. M. (2010). Evaluation of Stress Systems by Applying Noninvasive Methodologies : Measurements of Neuroimmune Biomarkers in the Sweat , Heart Rate Variability and Salivary Cortisol. NeurolmmunoModulation, 17, 205-208.

Masuri, M. G., Dahlan, A., Danis, A., \& Isa, K. A. (2017). Attitude towards Safe Driving Scale ( ASDS-46 ) as a Future Predictor in Determining a Young Adult Quality Of Life : Part II. Environment-Behaviour Proceedings Journal, 2(5), 363.

Masuri, M. G., Isa, K. A. M., \& Tahir, M. P. M. (2012). Children, Youth and Road Environment: Road Traffic Accident. Procedia - Social and Behavioral Sciences, 38(December 2010), 213-218.

McCombe, A. W. (2003). Hearing loss in motorcyclists: occupational and medicolegal aspects. Journal of the Royal Society of Medicine, 96(1), 7-9.

Norfazila, D., Mustaffa, A., \& Ghazali, M. (2017). Speeding Intention among Young Urban Drivers. Asian Journal of Behavioural Studies, AjBeS, 2 (7), 43-51.

Oiamo, T. H., Luginaah, I. N., \& Baxter, J. (2015). Cumulative effects of noise and odour annoyances on environmental and health related quality of life. Social Science \& Medicine, 146, 191-203. 
Repetti, R. L., Robles, T. F., \& Reynolds, B. (2011). Allostatic processes in the family. Development and Psychopathology, 23, 921-938.

Ross, B. C. (1989). Short Communication: NOISE EXPOSURE OF MOTORCYCLISTS. Annual Occupational Hygiene, 33(I), 123-127.

Saiyudthong, S., Suwannarat, P., Trongwongsa, T., \& Srisurapanon, S. (2010). Comparison between ECL and ELISA for the detection of salivary Cortisol and determination of the relationship between Cortisol in saliva and serum measured by ECL. ScienceAsia, 36, 169-171.

Salimetrics. (2014). High Sensitivity salivary cortisol. Retrieved from https://www.salimetrics.com/assets/documents/1-3002.pdf

Shepherd, D., Welch, D., Dirks, K. N., \& Mathews, R. (2010). Exploring the Relationship between Noise Sensitivity, Annoyance and Health-Related Quality of Life in a Sample of Adults Exposed to Environmental Noise. International Journal of Environmental Research and Public Health, 7, 3579-3594.

Shirtcliff, E. A., Buck, R. L., Laughlin, M. J., Hart, T., Cole, C. R., \& Slowey, P. D. (2015). Salivary Cortisol Results Obtainable Within Minutes of Sample Collection Correspond With Traditional Immunoassays. Clinical Therapeutics, 37(3), 505-514.

Stansfeld S A and Matheson M P. (2003). Noise pollution: non-auditory effects on health. British Medical Bulletin, 68(1), 243-257.

Stokholm, Z. A., Hansen, A. M., Grynderup, M. B., Peter, J., Lodberg, K., Winther, T., Kolstad, H. A. (2014). ScienceDirect Recent and long-term occupational noise exposure and salivary cortisol level. Psychoneuroendocrinology, 39, 21-32.

Sylvie Hebert, \& Lupien, S. J. (2009). Salivary cortisol levels, subjective stress, and tinnitus intensity in tinnitus sufferers during noise exposure in the laboratory. Int. J. Hyg. Environ.-Health, 212, 37-44.

Wagner, J., Cik, M., Marth, E., Santner, B. I., Gallasch, E., Lackner, A., \& Raggam, R. B. (2010). Feasibility of testing three salivary stress biomarkers in relation to naturalistic traffic noise exposure. International Jl of Hygiene and Environ Health, 213(2), 153-155. http://doi.org/10.1016/j.jiheh.2009.08.004

Waye, K. P., Bengtsson, J., Rylander, R., Hucklebridge, F., Evans, P., \& Clow, A. (2002). Low-frequency noise enhances cortisol among noise sensitive subjects during work performance. Life Sciences, 70, 745-758.

Weinstein, N. D. (1978). Individual differences in reactions to noise: a longitudinal study in a college dormitory. The Journal of Applied Psychology, 63(4), 458-466. World Health Organization. (2011). Burden of disease from environmental noise. Copenhagen. 